(C) 2022, The Authors. Published by Elsevier Inc. and Fass Inc. on behalf of the American Dairy Science Association ${ }^{\circledR}$. This is an open access article under the CC BY license (http://creativecommons.org/licenses/by/4.0/).

\title{
Defining clinical diagnosis and treatment of puerperal metritis in dairy cows: A scoping review
}

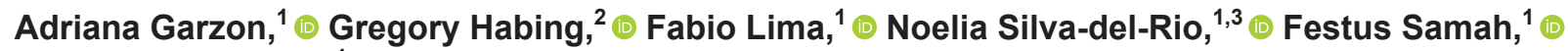 \\ and Richard Pereira ${ }^{1 *}$ \\ ${ }^{1}$ Department of Population Health and Reproduction, School of Veterinary Medicine, University of California, Davis, Davis 95616 \\ ${ }^{2}$ Department of Veterinary Preventive Medicine, Ohio State University, Columbus 43210 \\ ${ }^{3}$ Veterinary Medicine Teaching and Research Center, 18830 Road 112, Tulare, CA 93274
}

\section{ABSTRACT}

Although puerperal metritis (PM) is a common infectious disease in dairy cattle, there are currently discrepancies between clinical case definitions within and between available peer-reviewed literature and on-farms practices. The inconsistent use of PM criteria across studies and on-farms practices can result in disparities related to recommendations for treating cows, affecting judicious use of antimicrobials. The objective of this study was to systematically review the peer-reviewed literature for clinical signs used for case definition of PM. The criteria used included local (e.g., vaginal discharge) and systemic clinical signs of infection (e.g., fever, drop in milk). The Preferred Reporting Items for Systematic Review and Meta-Analysis extension for scoping reviews protocols were used to screen commonly used databases. Following this protocol, one reviewer screened title and abstract for eligibility $(\mathrm{n}=$ $2,096)$, followed by full-text screening of selected articles $(\mathrm{n}=396)$ by 2 reviewers to confirm eligible articles $(\mathrm{n}=174)$. The most frequently cited reference article (37.5\%) for the definition of PM was published in 2006, followed by articles published between 1998 and 2009 (13\%). In $40.2 \%$ of articles, no reference was provided for definition of PM; vaginal discharge was described in terms of color, odor, and viscosity when related to the PM definition. Terms used for description of vaginal discharge color were red-brown $(61.4 \%)$, red $(5.1 \%)$, brown $(8.6 \%)$, chocolate $(4 \%)$, white $(1.7 \%)$, yellow $(0.5 \%)$, pink $(5.7 \%)$, or gray $(0.5 \%)$; vaginal discharge color was not reported in $24.1 \%$ articles. The vaginal discharge odor was described as fetid $(75.8 \%)$, putrid (5.1\%), foul (10.3\%), or other $(5.7 \%$; e.g., abnormal, malodorous, odoriferous); odor was not mentioned in $7.4 \%$ of articles. The vaginal discharge viscosity was described as watery $(74.1 \%)$, purulent $(27 \%)$, mucopu-

Received August 24, 2021.

Accepted December 22, 2021.

*Corresponding author: rvpereira@ucdavis.edu rulent $(8.6 \%)$, thin $(4 \%)$, serous $(2.8 \%)$, or abnormal $(2.3 \%)$ and was not mentioned in $11.5 \%$ of articles. Fever was included in $59.7 \%$ of articles as a criterion for PM diagnosis. The most used rectal temperature threshold was $\geq 39.5^{\circ} \mathrm{C}(56.8 \%)$, followed by $\geq 39.2^{\circ} \mathrm{C}$ (2.8\%). Approaches used for vaginal discharge evaluation included rectal palpation $(37.3 \%)$, intravaginal exploration with a gloved hand (18.4\%), Metricheck (9.8\%), or speculum (5.7\%); and in $28.7 \%$ of articles, diagnostic tools used were not mentioned. Many of the color and odor vaginal discharge descriptions observed in the literature, used synonymous words to describe the same vaginal discharge sample, highlighting a lack of terminology consensus that could result in disagreements, especially due to the subjective character of these clinical evaluations of vaginal discharge color and odor. Although select consensus articles are available, it is common for studies to disregard a reference when defining PM cases. Furthermore, our findings highlight the need for a robust and clear consensus on criteria and terminology used to diagnose PM.

Key words: vaginal discharge, cattle, smell, viscosity, clinical definition, metritis, puerperal metritis

\section{INTRODUCTION}

Puerperal metritis (PM) is a common infectious disease in dairy cattle and the second most common reason for the treatment of a cow with antimicrobials (USDA, 2018). Metritis reduces herd profitability due to decreased milk production and reproductive efficiency and increased risk of early culling (Dubuc et al., 2011; de Oliveira et al., 2020). Metritis has also been negatively associated with animal welfare (Stojkov et al., 2015; Barragan et al., 2018; Neave et al., 2018). The estimated cost of PM includes therapeutic antimicrobial use, discarded milk, decreased milk yield, and decreased reproductive efficiency, among others (Lima et al., 2019).

A current area of contention related to PM is the case definition for clinical diagnosis in literature and on 
farms, which can result in misdiagnosis and unnecessary treatment of animals. A study evaluating current practices for PM treatment in 45 dairies in California reported a large variation in the clinical signs used for PM diagnosis and on the selection of antimicrobial treatment (Espadamala et al., 2018). This information gap has resulted in disparities in the definition, diagnosis, and treatment of cows affected by PM. The inconsistent criteria used to diagnose PM can result in misuse or overuse of antimicrobials on livestock farms and contribute to the emergence of antimicrobial-resistant bacteria, a focus area for which livestock production has received increasing attention.

Treatment of cows with PM has been supported to improve cows' production efficiency (de Oliveira et al., 2020). However, specific criteria for initiation of treatment as well as criteria to evaluate treatment success or disease cure is another area in which there are no clear guidelines. As a consequence, a lack of agreement on the criteria leading to start antimicrobial treatment on a cow with PM on farms is often observed (Espadamala et al., 2018).

Antimicrobial stewardship aims to preserve the effectiveness of antimicrobial drugs currently available through judicious antimicrobial use (AVMA Committee on Antimicrobials, 2020). As outlined in the American Veterinary Medical Association 2020 checklist for antimicrobial stewardship (AVMA, 2019), an important step to improve antimicrobial stewardship practices on the farm is to have "consensus-driven guidelines for diagnosis and therapy to manage bacterial infections." Although a definition for PM has been proposed in the literature by various authors (Sheldon et al., 2006), disagreement on the definition of PM in cows on farms (Espadamala et al., 2018) persists, limiting the progress of the industry toward refining and advancing in the accurate and prompt diagnosis of disease (USDA, 2008).

Scoping reviews aim to map relevant literature and available evidence on specific research topic areas (Arksey and O'Malley, 2005) and can be undertaken to determine the extent, and range of research activity available, by summarizing and disseminating research findings and identifying research knowledge gaps in the existing literature (Arksey and O'Malley, 2005). The main objective of this scoping review was to thoroughly and systematically evaluate the criteria used for case definitions for PM in peer-reviewed manuscripts. Specific criteria used for reference included specific visual signs of PM (e.g., vaginal discharge) and systemic signs of infection (e.g., fever, drop in milk). The second objective of this project was to identify the threshold criteria used to determine the need for therapeutic intervention for cows diagnosed with PM.

\section{METHODS}

A protocol was developed following the Preferred Reporting Items for Systematic Reviews and MetaAnalyses extension for scoping reviews (Tricco et al., 2018) and the scoping review framework described by Arksey and O'Malley (Arksey and O'Malley, 2005). Our research questions were as follows: What are the clinical criteria used in the diagnosis of PM in dairy cows, and what are the clinical criteria to support a therapeutic intervention in those animals?

\section{Information Sources and Search Strategy}

The literature search was conducted using MEDLINE and PubMed (https://pubmed.gov), CAB Abstracts (https://CABI.org), Scopus (https://scopus.com), and Web of Science (https://clarivate.com) online databases between February 13 and 19, 2019. The search strategy was designed in MEDLINE and PubMed and CAB Abstracts and adapted to each database with support from University of California-Davis librarians at the Carlson Health Sciences Library in the School of Veterinary Medicine. The search included terms related to the population of interest (dairy cattle) and the disease of interest (PM). The final search strategy for the PUBMED database is described in Table 1. Searches included all available years of the databases and geographical locations, and were restricted to English as the language for publication. All citations were downloaded to EndNote (Version X9 for Windows, Thomson Reuters) for de-duplication. De-duplicated citations were imported into DistillerSR software Version 2.35 (Evidence Partners Inc.) for relevance screening.

\section{Selection of Sources of Evidence}

Eligibility criteria included peer-reviewed primary research studies that performed the diagnosis of PM, that used dairy cows as their study population and only studies published in the English language. Review studies (e.g., narrative, systematic, scoping review), postmortem, and in vitro studies were excluded from the systematic scoping review.

Titles and abstracts of all the identified references were assessed by one reviewer, who screened these studies for eligibility (AG). The term "screening" is used through this manuscript, to refer to the 2-step process of identifying the relevant studies from the literature search that were included in the scoping review (Tricco et al., 2018). Inclusion was assessed by answer "yes," "no," or "unclear" to the following questions: (1) does the title or abstract mention PM as the disease of inter- 
Table 1. Outline of items included in the search strategy for clinical signs used as diagnostic criteria for puerperal metritis

\begin{tabular}{ll}
\hline $\begin{array}{l}\text { Grouping } \\
\text { factor }\end{array}$ & Search item" \\
\hline 1 & "postpartum period"[MeSH] OR "postpartum"[tiab] OR "post partum"[tiab] OR postnatal[tiab] OR "post natal"[tiab] OR \\
& parturient[tiab] OR "post birth"[tiab] OR "puerperal disorders"[MeSH] OR "puerperal"[tiab] OR "puerperium"[tiab] OR \\
& "parturition"[MeSH Terms] OR "parturition"[tiab] \\
2 & "uterus"[MeSH] OR "uterus"[tiab] OR "uterine"[tiab] OR uteral[tiab] \\
3 & "infection"[MeSH] OR "infection"[tiab] OR "infections"[tiab] OR "inflammation"[MeSH] OR "inflammation"[tiab] \\
& OR "inflammations"[tiab] OR infected[tiab] OR "disease"[MeSH] OR "disease"[tiab] OR "diseases"[tiab] OR "vaginal \\
4 & discharge"[tiab] OR "fever"[MeSH] OR "fever"[tiab] OR "disorder"[tiab] OR "disorders"[tiab] \\
5 & 1 AND 2 AND 3 \\
6 & Metritis \\
7 & "cattle"[MeSH] OR "cattle"[tiab] OR "cow"[tiab] OR "cows"[tiab] OR Bos[tiab] \\
8 & 6 AND (5 OR 4)
\end{tabular}

$\overline{{ }^{1} \mathrm{MeSH}}=$ Medical Subject Headings thesaurus, controlled and hierarchically organized vocabulary produced by the National Library of Medicine used for indexing articles for PubMed; tiab = limit to title or abstract.

est?; (2) does the title or abstract mention dairy cows as the study population?; (3) is the study a primary research study or nonreview article (narrative, systematic, meta-analysis)?; and (4) is the study an in vivo study (not an in vitro experiment or a postmortem study)?

Relevance screening of the full-text articles was conducted for the references answering "yes" or "unclear" in all questions on the titles and abstract screening. The complete manuscripts for studies fulfilling the selection criteria were imported into DistillerSR and screened independently by 2 reviewers (AG, FS). Inclusion was assessed by answer "yes" or "no" to the following questions: (1) is the full-text article available in English?; (2) are dairy cows the study population?; (3) is the study a primary research study or nonreview article (narrative, systematic, meta-analysis)?; (4) is the study an in vivo study (not an in vitro experiment or a postmortem study)?; and (5) is PM defined in the study, or the diagnosis criteria of metritis is stated)?

Pretesting for relevance screening was conducted on 15 randomly selected studies based on the full text, following a DistillerSR form, to ensure consensus between reviewers. Studies for which disagreements for including were reached between the 2 reviewers were reviewed by a third reviewer, blinded to the position of either one of the 2 reviewers (RP).

\section{Data Charting}

Data charting was conducted by one reviewer (AG) following a predesigned DistillerSR form. The form was pretested on 10 studies to ensure all relevant data were extracted. Data charting was conducted using the full article text, and for this reason, data charting was only performed on references in which the full text was available.

\section{Data Items}

Characteristics of relevant studies were extracted, including type of study, method of sample selection, breed, and study location (Table 2). Data charted for PM diagnosis included the main author cited for the definition of PM, DIM range used for diagnosis, method of vaginal discharge collection, vaginal discharge characteristics, systemic signs of disease used for diagnosis, sampling frequency, diagnostic tools, and the person conducting the diagnosis of sick animals (Table 2).

\section{Data Synthesis}

To evaluate the main variables used for the diagnosis of PM and factors that resulted in the decision to treat a cow with PM, descriptive statistics, and multiple correspondence analyses were computed using JMP Pro 15.0.0 (SAS Institute Inc.). Multiple correspondence analysis was used to evaluate the association among categorical variables for the definition and diagnosis of PM and year of publication of the studies. Items offered to the analysis included viscosity (if only watery, it was termed "watery"; if watery and purulent, "watery \& purulent"; if only purulent, "purulent"; if not mentioned, "no_viscosity") and smell (if fetid, "fetid_y"; if not, "fetid_n") of vaginal discharge, DIM ("0 - 7 DIM," "0 - 14 DIM," "0 - 21 DIM," " > 21 DIM," or if DIM not mentioned, "No_DIM"), presence of fever (if yes, "fever_y"; if no, "fever_n") and year of publication (if published before 2006, "before_2006"; between 2006 and 2010, "After_2006"; or after 2010, "After_2010").

\section{Risk of Bias Assessment}

Risk of bias (ROB) was assessed for each article using the SYRCLE Risk of Bias tool for animal studies (Hooijmans et al., 2014). The chosen outcome for the 
ROB given the objectives of the review, was the treatment of cows diagnosed with metritis and reporting of treatment success; therefore, ROB was performed on the 32 experimental studies (randomized controlled trials) where treatment for metritis was describe. Five different sources of bias were assessed: selection, performance, detection, attrition, and reporting bias. Signaling questions were modified for the use in livestock studies, as has been previously described (Sargeant and O'Connor, 2014; Sargeant et al., 2019). Signaling questions were also modified to include the evaluation of disease and disease cure definitions. All signaling questions are described in Supplemental Table S1 (https:// doi.org/10.5281/zenodo.5576632; Garzon et al., 2021).

\section{RESULTS}

\section{Selection of Sources of Evidence}

After the search, 2,096 publications were retrieved. Of those, $396(18.9 \%)$ were identified as relevant after title and abstract screening and were selected for full-text evaluation. There were 174 full-text articles considered relevant for data charting using this review protocol (Figure 1). The complete list of references included for data charting is described in the Supplemental File S1 (https://doi.org/10.5281/zenodo.5576632; Garzon et al., 2021).

\section{Study Characteristics}

Relevant studies included observational studies (n $=115 ;$ cross-sectional studies, $\mathrm{n}=15$, prospective case-control studies, $\mathrm{n}=22$, retrospective case-control studies, $\mathrm{n}=1$, prospective cohort studies, $\mathrm{n}=67$, and retrospective cohort studies, $\mathrm{n}=10$ ). Relevant studies also included 54 experimental studies, of which 39 were randomized controlled trials, case reports or case series $(\mathrm{n}=4)$, and one survey $(\mathrm{n}=1)$. Studies were conducted in North America $(\mathrm{n}=83$; United States, $\mathrm{n}$ $=63$, and Canada, $\mathrm{n}=22)$, Europe $(\mathrm{n}=52)$, Asia $(\mathrm{n}$ $=27)$, South America $(\mathrm{n}=9)$, Africa $(\mathrm{n}=2)$ and New Zealand $(\mathrm{n}=1)$. In the United States, most studies were conducted in Florida $(\mathrm{n}=20)$, New York $(\mathrm{n}=$ 19), or California ( $\mathrm{n}=4$ ). In Europe, Germany ( $\mathrm{n}=$ 22) had the most studies conducted.

All relevant studies selected their herds by convenience. Most studies $(\mathrm{n}=166)$ enrolled cows within the herd by convenience. The sample size calculation approach was described in 96 studies. However, for experimental studies $(\mathrm{n}=52)$, only 23 studies described any sample size calculation. Randomization was reported in 35 of the 52 experimental studies, although the randomization strategy was not described in 10 studies. Blinding of the personnel on the randomized controlled trails was describe in 26 of the 52 experimental studies. Relevant studies enrolled one herd $(\mathrm{n}=120), 2$ to $\leq 50$

Table 2. Description of data item charted from the included references

\begin{tabular}{ll}
\hline Variable & Description \\
$\begin{array}{l}\text { Study characteristic } \\
\text { Type of study }\end{array}$ & $\begin{array}{l}\text { Experimental study (randomized controlled trial), observational study (case control, cohort), survey, case report or } \\
\text { case series }\end{array}$ \\
$\begin{array}{l}\text { Rample selection } \\
\text { Breed }\end{array}$ & $\begin{array}{l}\text { Holstein, Jersey, crossbred, other, not mentioned } \\
\text { Country and region where the study was conducted }\end{array}$ \\
$\begin{array}{l}\text { Study location } \\
\text { Reference for metritis }\end{array}$ & $\begin{array}{l}\text { Chenault et al., 2004; Elkjær et al., 2013; Gorden et al., 2016; Piccardi et al., 2016; Sannmann et al., 2013; Sheldon } \\
\text { et al., 2006; Urton et al., 2005; Other; Not mentioned }\end{array}$ \\
$\begin{array}{l}\text { Metritis diagnosis } \\
\text { DIM }\end{array}$ & $\begin{array}{l}\text { Days after calving } \\
\text { Color of VD }\end{array}$ \\
Viscosity of VD & Watery, thin, serous, viscous, mucopurulent, purulent, other, not mentioned \\
Odor of VD & Fetid, putrid, foul, other, not mentioned \\
Uterus & Abnormally enlarged, flacid, other, not mentioned \\
Fever & Rectal temperature $\geq 39.2^{\circ} \mathrm{C}, \geq 39.5^{\circ}$ C, other, not mentioned \\
Clinical signs & Dehydration, drop in milk yield, depression, tachycardia, tachypnea, anorexia (off feed), other, none \\
Sampling frequency & Daily, once per week, twice per week, one time during the study, other, not mentioned \\
Diagnostic tools & Metricheck, speculum, rectal palpation massage, gloved hand, other, not mentioned \\
Evaluator & Farm veterinarian, employee, owner, researcher, other, not mentioned
\end{tabular}

${ }^{1}$ Experimental study: study in which an intervention is introduce and the effects of the intervention are studied. Randomized controlled trial: subjects are randomly assigned to a intervention or control group and any differences in the outcome of interest is measure and linked to the intervention. Observational study: no intervention or attempt to affect the outcome of interest is made. Subjects of interests are observed and outcomes of interests measured. Observational studies include cohort and case-control studies. Cohort study: type of observational study in which the outcome of interest is compare in the cohort of individuals based on exposures of interest (risk factor). Case-control study: type of observational study comparing 2 groups of individuals; those with the condition of interest (cases) and very similar groups without the outcome of interest (controls) are compared with identify factors that may be associated with the outcome (Gordis, 2009).

${ }^{2} \mathrm{VD}=$ vaginal discharge. 


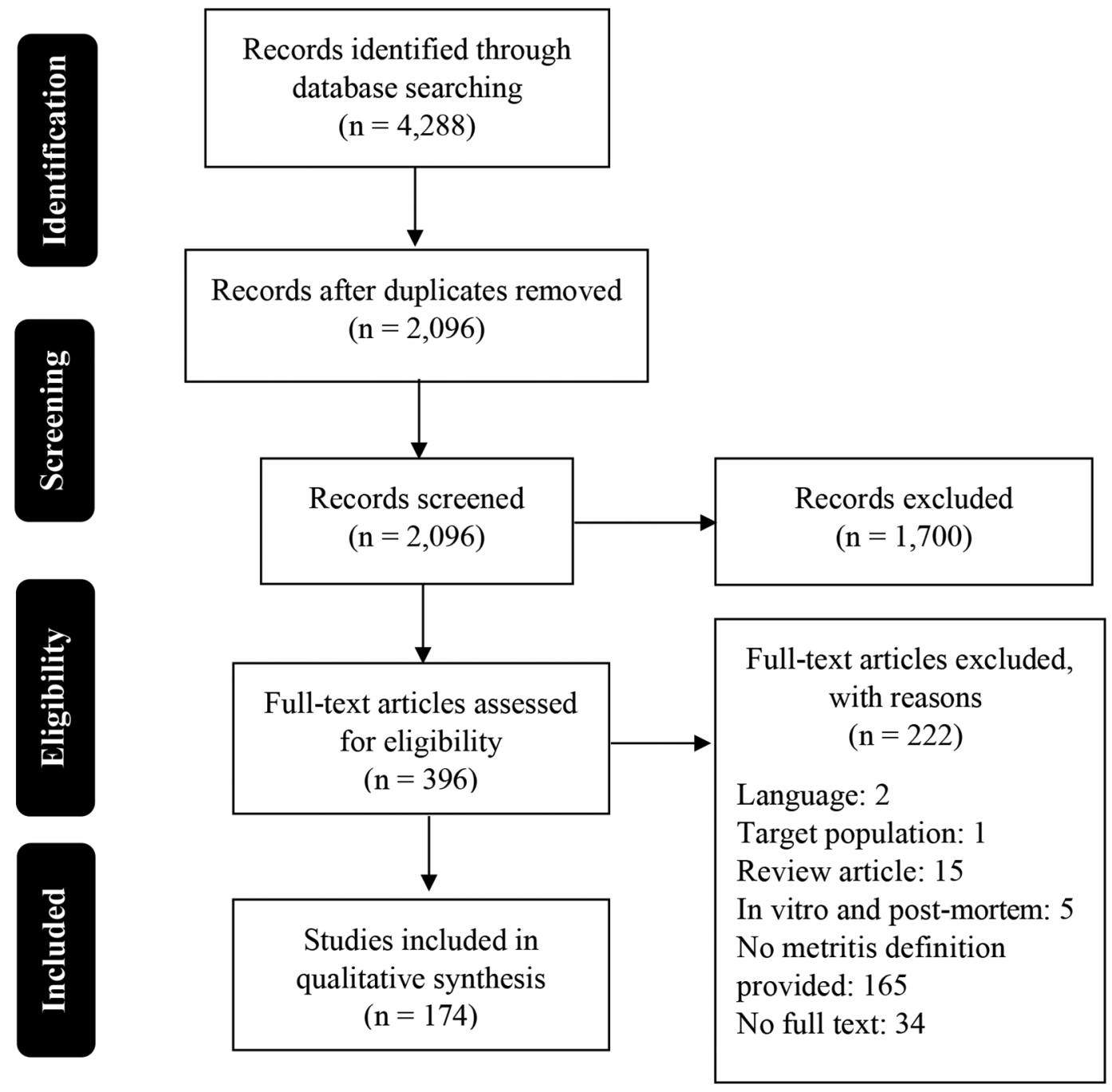

Figure 1. Preferred Reporting Items for Systematic Reviews and Meta-Analyses (PRISMA) flow diagram for clinical criteria used for defining puerperal metritis and therapeutic treatment threshold in dairy cows.

herds $(\mathrm{n}=48)$, or $>50$ herds $(\mathrm{n}=5)$. The number of animals included in the relevant studies ranged between 5 and 282,099 cows, with a median of 117 animals per study. The studies enrolled Holstein $(\mathrm{n}=125)$, Holstein and Jersey $(\mathrm{n}=12)$, Holstein and Jersey crossbred ( $\mathrm{n}$ $=5)$, other dairy breeds $(\mathrm{n}=3)$, or breeds were not reported $(\mathrm{n}=29)$.

\section{Synthesis of Results}

The references used to support PM definitions are described in Table 3. The most common reference used to support PM definition was Sheldon et al. (2006) cited in 65 relevant studies. Seventy studies did not provide a citation for PM definition. In contrast, 10 studies cited 2 or more references, including Chenault et al. (2004), Huzzey et al. (2007), Smith et al. (1998), and Benzaquen et al. (2007) that were cited in 9, 5, 3, and 3 relevant studies, respectively. Twenty-six references were used to define PM only once or twice in the relevant studies. Most of the relevant studies were published after $2006(\mathrm{n}=135)$, the year in which the most commonly cited study was published (Sheldon et al., 2006), whereas $22.4 \%$ of the relevant studies were published before $2006(\mathrm{n}=39)$.

Relevant studies evaluated cows for PM at 0 to 7 $\operatorname{DIM}(6.3 \%, \mathrm{n}=11), 0$ to $14 \operatorname{DIM}(41.4 \%, \mathrm{n}=72), 0$ to $21 \operatorname{DIM}(39.7 \%, \mathrm{n}=69)$, or 0 to $>21 \operatorname{DIM}(4 \%, \mathrm{n}=7)$. However, some studies $(8.6 \% ; \mathrm{n}=15)$ did not indicate the time of PM diagnosis (Table 4).

Vaginal discharge was obtained after massaging the uterus through the rectum $(37.4 \%, \mathrm{n}=65)$, performing intravaginal exploration with a gloved hand $(18.4 \%$, $\mathrm{n}=32$ ), using the Metricheck device (Simcrotech, 
Table 3. Authors cited as a reference for the definition of puerperal metritis in dairy cows

\begin{tabular}{lrc}
\hline Author & $\mathrm{n}$ & $\%$ \\
\hline Not mentioned & 70 & 40.2 \\
Sheldon et al. (2006) & 65 & 37.4 \\
Chenault et al. (2004) & 9 & 5.2 \\
Huzzey et al. (2007) & 5 & 2.9 \\
Benzaquen et al. (2007) & 2 & 1.1 \\
Sheldon et al. (2008) & 3 & 1.7 \\
Smith et al. (1998) & 3 & 1.7 \\
Elkjær et al. (2013) & 3 & 1.7 \\
Drillich et al. (2007) & 2 & 1.1 \\
Hammon et al. (2006) & 2 & 1.1 \\
Jeon et al. (2015) & 2 & 1.1 \\
LeBlanc (2008) & 2 & 1.1 \\
Lima et al. (2014) & 2 & 1.1 \\
Urton et al. (2005) & 2 & 1.1 \\
Dohmen et al. (1995) & 1 & 0.6 \\
Drillich et al. (2001) & 1 & 0.6 \\
Giuliodori et al. (2013) & 1 & 0.6 \\
Martinez et al. (2012) & 1 & 0.6 \\
McDougall et al. (2007) & 1 & 0.6 \\
McLaughlin et al. (2013) & 1 & 0.6 \\
Murray et al. (1990) & 1 & 0.6 \\
Sheldon et al. (2002) & 1 & 0.6 \\
Sheldon and Noakes (1998) & 1 & 0.6 \\
Stangaferro et al. (2016) & 1 & 0.6 \\
Williams et al. (2005) & 1 & 0.6 \\
\hline
\end{tabular}

Hamilton, New Zealand) $(9.8 \%, \mathrm{n}=17)$, or a vaginal speculum $(5.7 \%, \mathrm{n}=10)$. The method used to obtain vaginal discharge was not described in $28.7 \%(\mathrm{n}=$ 50) of the relevant studies. The diagnosis of PM was performed by researchers $(\mathrm{n}=85)$, employees $(\mathrm{n}=$ $37)$, farm veterinarians $(\mathrm{n}=35)$, and owners $(\mathrm{n}=1)$. Sixteen studies did not report the identity of the person performing PM diagnosis. (Table 5). Cows were evaluated for PM with different frequencies: daily during

Table 4. Days in milk, sampling frequency, and diagnostic tools used as diagnostic criteria for puerperal metritis in dairy cows

\begin{tabular}{lrr}
\hline Variable & $\mathrm{n}$ & $\%$ \\
\hline DIM & & \\
$0-7$ & 11 & 6.3 \\
$0-14$ & 72 & 41.4 \\
$0-21$ & 69 & 39.7 \\
$>21$ & 7 & 4.0 \\
Not mentioned & 15 & 8.6 \\
Diagnostic tool & & \\
Rectal palpation & 65 & 37.4 \\
Gloved hand & 32 & 18.4 \\
Metricheck & 17 & 9.8 \\
Speculum & 10 & 5.7 \\
Not mentioned & 50 & 28.7 \\
Sampling frequency & & \\
Daily & 41 & 23.6 \\
Once per week & 13 & 7.5 \\
Twice per week & 7 & 4.0 \\
One time during the study & 28 & 16.1 \\
Other & 57 & 32.8 \\
Not mentioned & 26 & 14.9 \\
\hline
\end{tabular}

Journal of Dairy Science Vol. 105 No. 4, 2022
Table 5. Distribution of characteristics of vaginal discharge used for the definition of puerperal metritis in dairy cows $^{1}$

\begin{tabular}{lrr}
\hline Variable & $\mathrm{n}$ & $\%$ \\
\hline Odor & & \\
Fetid & 132 & 75.9 \\
Foul & 18 & 10.3 \\
Putrid & 9 & 5.2 \\
Other & 10 & 5.7 \\
Not mentioned & 13 & 7.5 \\
Color & & \\
Red-brown & 107 & 61.5 \\
Brown & 15 & 8.6 \\
Pink & 10 & 5.7 \\
Red & 9 & 5.2 \\
Chocolate & 7 & 4.0 \\
White & 3 & 1.7 \\
Yellow & 1 & 0.6 \\
Gray & 1 & 0.6 \\
Abnormal & 7 & 4.0 \\
Not mentioned & 42 & 24.1 \\
Viscosity & & \\
Watery & 129 & 74.1 \\
Purulent & 47 & 27.0 \\
Mucopurulent & 15 & 8.6 \\
Thin & 7 & 4.0 \\
Serous & 5 & 2.9 \\
Abnormal & 4 & 2.3 \\
Not mentioned & 20 & 11.5 \\
\hline Sel sties & &
\end{tabular}

${ }^{1}$ Select studies used multiple criteria; therefore, the total number is not equal to the number of articles included in the scoping review.

fresh cows' checks $(23.6 \%, \mathrm{n}=41)$, one time during the study $(16.1 \%, \mathrm{n}=28)$, once per week $(7.5 \%, \mathrm{n}=$ 13 ), or twice per week $(4 \%, \mathrm{n}=7$ ). However, $32.8 \%$ ( $\mathrm{n}$ $=57$ ) of relevant studies evaluated cows following 39 different sampling frequencies strategies, and $14.9 \%$ (n $=26$ ) of the relevant studies did not report sampling frequency (Table 4).

The definition of PM included abnormal odor, color, and viscosity of vaginal discharge (Table 5). The odor of the vaginal discharge was considered indicative of PM if it was fetid $(75.9 \%, \mathrm{n}=132)$, foul $(10.3 \%, \mathrm{n}=$ 18 ), putrid $(5.2 \%, \mathrm{n}=9)$, or other (e.g., abnormal, malodorous, odoriferous, offensive, or smelly; $5.7 \%, \mathrm{n}$ $=10$ ). The discharge odor was not included as a criterion for the definition of PM in $7.5 \%(\mathrm{n}=13)$ of the relevant studies. The color of the vaginal discharge of cows with PM was defined as red-brown $(61.5 \%, \mathrm{n}=$ 107), brown $(8.6 \%, \mathrm{n}=15)$, pink $(5.7 \%, \mathrm{n}=10)$, red $(5.2 \%, \mathrm{n}=9)$, chocolate $(4 \%, \mathrm{n}=7)$, white $(1.7 \%, \mathrm{n}$ $=3)$, yellow $(0.6 \%, \mathrm{n}=1)$, or gray color $(0.6 \%, \mathrm{n}=$ 1). Forty-two (24.1\%) studies did not report the color of the vaginal discharge. The viscosity of the vaginal discharge of cows with PM was described as watery $(74.1 \%, \mathrm{n}=129)$, purulent $(27 \%, \mathrm{n}=47)$, mucopurulent $(8.6 \%, \mathrm{n}=15)$, thin $(4 \%, \mathrm{n}=7)$, serous $(2.9 \%, \mathrm{n}=$ $5)$, or abnormal $(2.3 \%, \mathrm{n}=4)$. However, some studies $(11.5 \% ; \mathrm{n}=20)$ did not evaluate the viscosity of the vaginal discharge. 


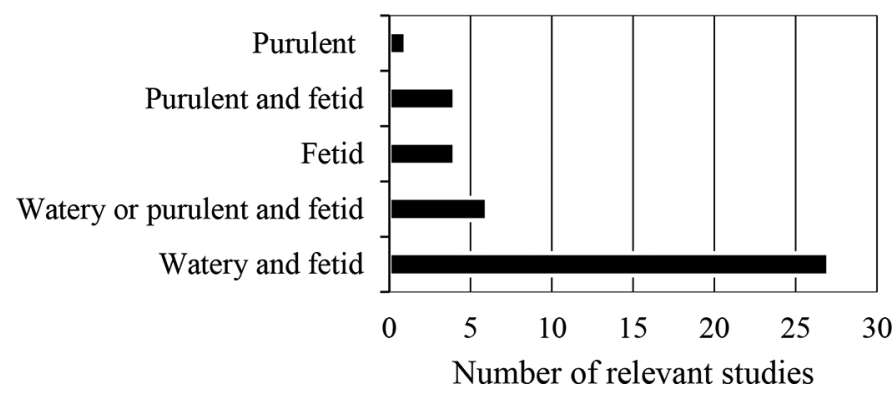

Figure 2. Vaginal discharged characteristics for 42 studies, including clinical cure or treatment decision data $(\mathrm{n}=42)$.

Rectal temperature was included as a diagnostic criterion for PM in some relevant studies $(59.7 \%$, n $=104)$, with a threshold of $\geq 39.5^{\circ} \mathrm{C}(56.8 \%, \mathrm{n}=99)$ or $\geq 39.2^{\circ} \mathrm{C}(2.8 \%, \mathrm{n}=5)$. Even though some relevant studies evaluated rectal temperature $(39.6 \%, \mathrm{n}=69)$, they did not use this information as a diagnostic criterion. One of the relevant studies included fever as a diagnostic criterion but without describing the threshold used. Although most studies $(71.2 \%, \mathrm{n}=124)$ did not include signs of systemic disease to define PM, some included dehydration $(6.8 \%, \mathrm{n}=12)$, decreased milk production $(12.6 \%, \mathrm{n}=22)$, depression $(9.7 \%, \mathrm{n}=17)$, tachycardia $(2.3 \%, \mathrm{n}=4)$, tachypnea $(2.3 \%, \mathrm{n}=4)$, signs of toxemia $(4 \%, \mathrm{n}=7)$, decreased appetite $(4.6 \%$, $\mathrm{n}=8)$, and unspecified signs of systemic illness $(6.3 \%$, $\mathrm{n}=11$ ). Fifty relevant studies mentioned systemic signs of disease, although just a few studies required at least one $(3.4 \%, \mathrm{n}=6), 2(2.3 \%, \mathrm{n}=4)$, or 3 or more $(1.1 \%$, $\mathrm{n}=2$ ) systemic signs of disease to define a PM case.

The type of treatments used for PM was described in 42 relevant studies, including 32 randomized controlled trials, one survey, 3 observational retrospective cohort studies, and 6 observational prospective cohort studies
(Table 6). Treatment decisions included an abnormal vaginal discharge as the main criteria to initiate treatment in 41 of the 42 relevant studies. Different definitions of abnormal vaginal discharges were described, that for this study, were grouped into 5 categories (Figure 2). Furthermore, treatment decisions were also made based on the simultaneous presence of systemic signs of disease or fever, as described in Table 6. These 42 relevant studies defined clinical cure based on normal vaginal discharge $(26.2 \%, \mathrm{n}=11)$, normal vaginal discharge and no fever $(14.3 \%, \mathrm{n}=6)$, no fever $(11.9 \%$, $\mathrm{n}=5$ ), normal vaginal discharge and no systemic signs of disease $(2.4 \%, \mathrm{n}=1)$, or no systemic signs of disease $(2.4 \%, \mathrm{n}=1)$. However, in $42.9 \%(\mathrm{n}=18)$ of these studies, the definition of PM cure was no reported.

To evaluate the most frequently used clinical criteria for defining PM on the relevant studies, and their association with the year of publication of the relevance studies; the variables of viscosity and smell of vaginal discharge, DIM at diagnosis, presence of fever, and year of publication of the studies were used for the multiple correspondence analysis. The map is shown in Figure 3. The first 2 dimensions of the analysis accounted for a higher proportion of the inertia of the data. When reading left to right along the $\mathrm{x}$-axis of the map, the first dimension shows a strong association between smell and viscosity of the vaginal discharge with the DIM for inclusion. This dimension shows how a watery and fetid vaginal discharge is strongly associated with disease diagnosis within the first 14 DIM, whereas a vaginal discharge categorized as purulent and not fetid, in addition to no fever, is associated with diagnosis included up to 21 DIM. When reading top to the bottom of the map, along the y-axis, the second dimension differentiates between the characteristics of vaginal discharge, the DIM at PM evaluation, and the year of publication. In relevant studies published after 2006 (especially after

Table 6. Distribution of clinical criteria used for treatment decision and definition of cure of puerperal metritis in dairy cows; this is data from a subset of articles that included clinical cure or treatment decision data (n $=42)$

\begin{tabular}{lrr}
\hline Variable & $\mathrm{n}$ & $\%$ \\
\hline Treatment decision & & \\
Systemic signs of disease, fever, and abnormal vaginal discharge & 4 & 9.5 \\
Systemic signs of disease and abnormal vaginal discharge & 1 & 2.4 \\
Fever and abnormal vaginal discharge & 20 & 47.6 \\
Abnormal vaginal discharge only & 16 & 38.1 \\
Cows in higher risk of metritis & 1 & 2.4 \\
Definition of cure & 6 & 14.3 \\
Normal vaginal discharge and no fever & 1 & 2.4 \\
Normal vaginal discharge and no systemic signs of disease & 5 & 11.9 \\
No fever & 11 & 26.2 \\
Normal vaginal discharge & 1 & 2.4 \\
No systemic signs of disease & 18 & 42.9 \\
Not mentioned & & \\
\hline
\end{tabular}




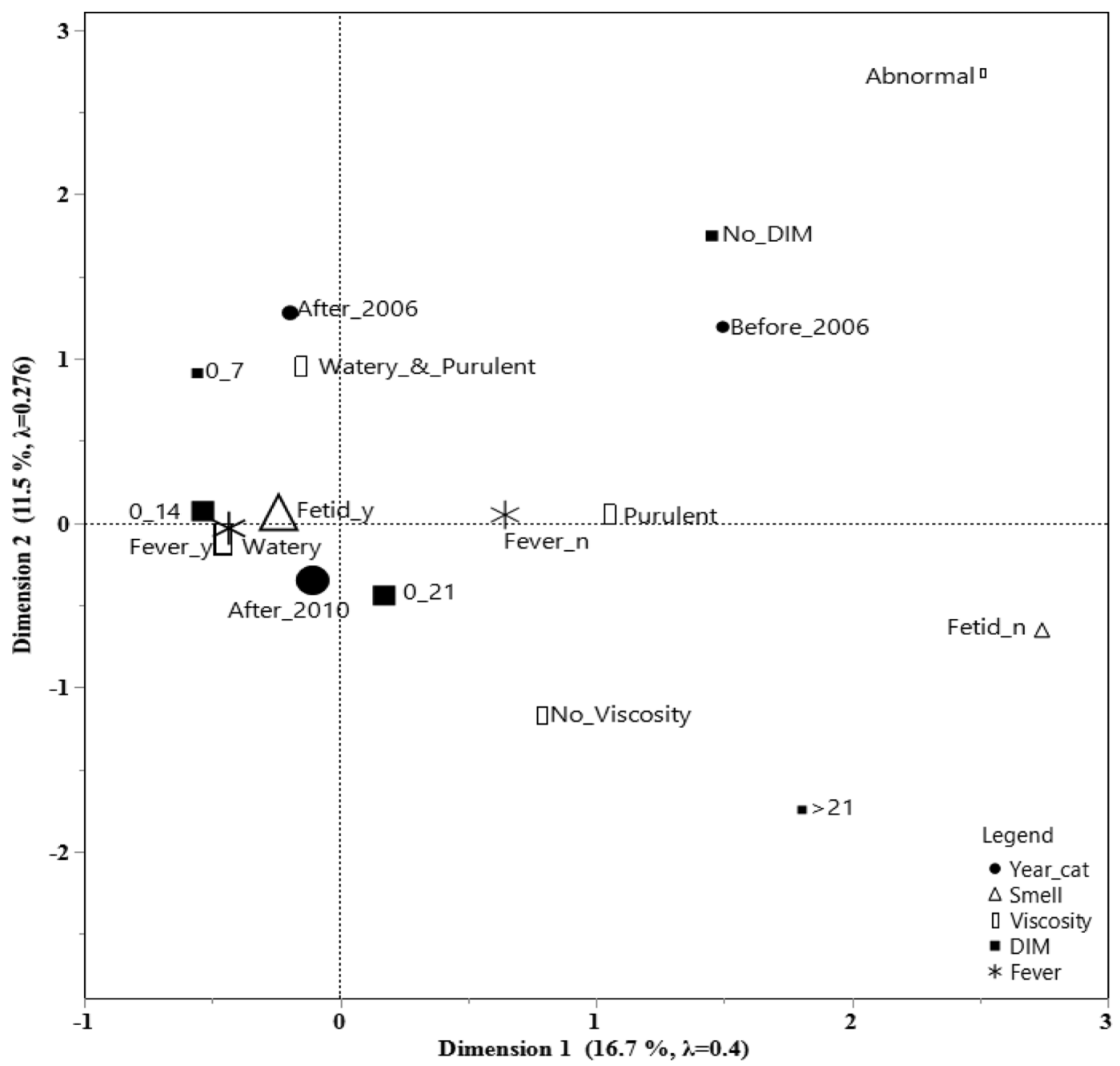

Figure 3. Map of multiple correspondence analysis results evaluating the associations among the categories for viscosity and smell of vaginal discharge (VD), DIM, presence of fever, and year of publication. The size of the points in the plot are proportional to the count of observations corresponding to each variable response. The parenthesis for each dimension represents, respectively, the percent proportion of inertia and the inertia $(\lambda)$, which reflect the relative variation explained for each dimension. Smell: fetid VD (Fetid_y) or not fetid VD (Fetid_n). Viscosity: watery VD (Watery), watery and purulent VD (Watery andP), purulent VD (purulent), viscosity not mentioned (No_viscosity). Fever: presence of fever (Fever_y) or no fever (Fever_n). DIM: 0 to 7 DIM, 0 to 14 DIM, 0 to 21 DIM, >21 DIM, DIM not mentioned (No_DIM). Year: references published before 2006 (Before_2006), between 2006 and 2010 (After_2006), or after 2010 (After_2010).

2010), watery and fetid vaginal discharge were associated with PM definition. Relevant studies published before 2006 were less clear regarding the inclusion of DIM at evaluation, the odor, and the viscosity (watery and purulent consistency) of the vaginal discharge as part of PM definition.

\section{Risk of Bias Assessment}

Results of the ROB assessment are shown at the study level in Supplemental Table S2 (https://doi.org/ 10.5281/zenodo.5576632; Garzon et al., 2021), and the proportion across all included studies for the second objective of the review (Figure 4).

\section{DISCUSSION}

The puerperium is the period between birth and the completion of uterine involution (Stevenson, 2007). Puerperal metritis for the aim of this scoping review is used to refer to the postpartum period, therefore, PM includes metritis with systemic clinical signs (in some relevance reference mention as puerperal, acute, septic, or toxic metritis), or PM without systemic clinical signs.

This scoping review identified published literature available for the definition and diagnosis of dairy cattle with PM, showing a disparity in the definition and clinical signs of disease used in research for on-farm 


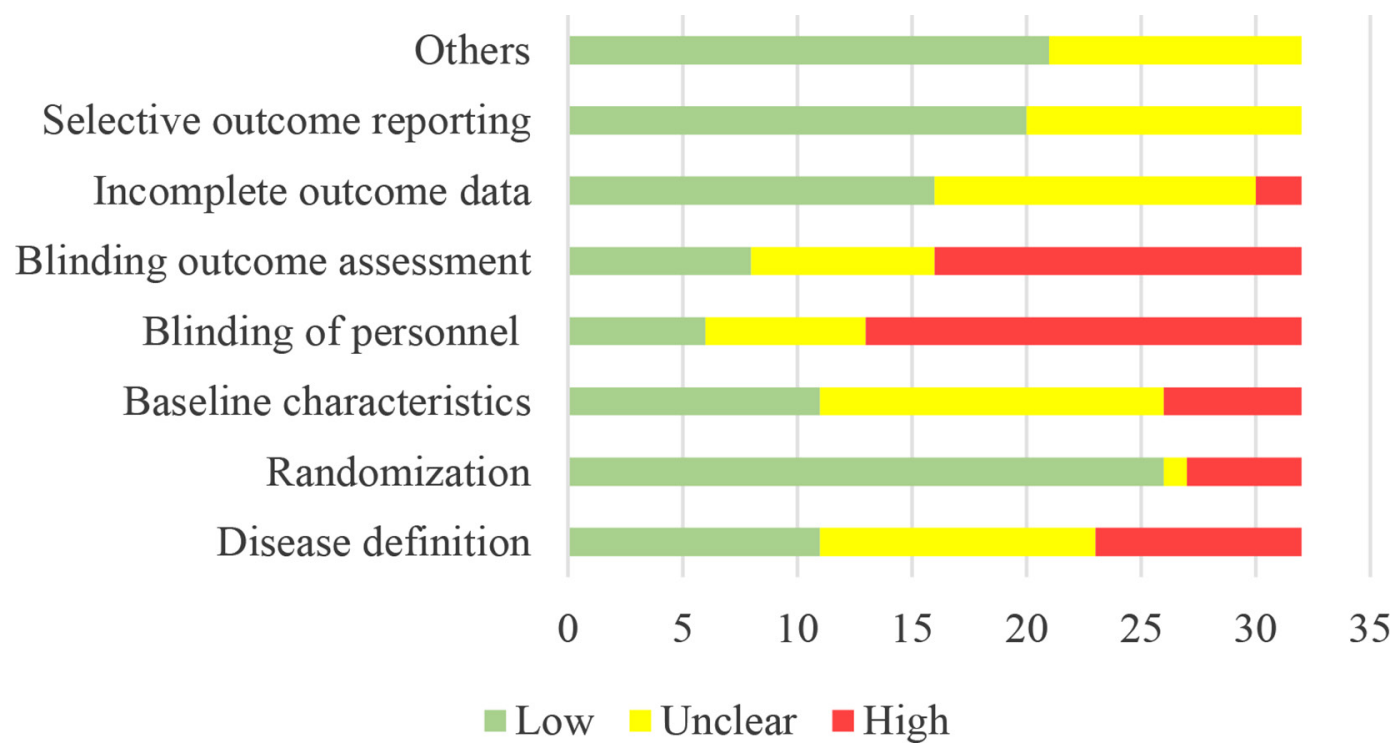

Figure 4. Risk of bias assessment across included studies for the treatment of metritis $(\mathrm{n}=32)$.

diagnosis of PM. Sheldon et al. (2006) has been an essential reference toward standardizing the definition of PM and represented a substantial effort using the best available data and experts consensus at the time to create consistency when referencing postpartum uterine diseases in cattle; evidence of this effort include the fact that this study served as a reference for multiple publications included in the final scoping review. However, the proposed definition was also based in this landmark article by Sheldon et al. (2006), as well as following articles in the same timeline, resulted in a clear temporal disparity by year for PM, observed in the multiple correspondence analysis (Figure 3) for various criteria. Efforts toward a standardization of the definition of PM can be viewed from the evident clustering for criteria used to define PM observed for articles published after 2006. Publications more frequently used the presence of a watery and fetid discharge and the presence or absence of fever in cows $\leq 14$ DIM into consideration when defining PM. This finding supports temporal progress in literature toward the use of consistent criteria for case definition for PM. Nonetheless, over one-third of the studies included purulent or mucopurulent vaginal discharge as indicators of PM, whereas in other studies smell was not assessed, which highlights opportunities for improvement, including a more standardized vocabulary use when defining color, smell, and viscosity of vaginal discharge. The top 5 articles that served as references for defining PM were published before 2010, and a multitude of new evidence-based data has been generated since; findings from our study summarize current definition disparities and highlight opportunity to focus future efforts to integrate novel data to continue improving the accuracy and consistency when defining PM in academic and field settings.

Multiple factors used in the clinical case definition of PM by Sheldon et al. (2006) and similar following articles were based on subjective visual and sensory assessment of variables that have not been validated, including vaginal discharge color and smell. Sannmann and Heuwieser (2015), evaluated the sensory assessment of color, odor, and viscosity of vaginal discharge using 15 investigators input. Each investigator independently evaluated 6 different vaginal discharges, following a 5-point scale score. The study concluded that the classification of the vaginal discharge had a fair to moderate overall intra-observer reliability and slight to fair overall interobserver reliability (Sannmann and Heuwieser, 2015). Definition and diagnosis of PM in onfarm settings need to improve standardization and reduce subjectivity to improve antimicrobial stewardship. Future research should include current evidence-based data available and focus on validating and evaluating the accuracy and consistency of different combinations of diagnostic approaches currently used for PM, and identifying novel tools that increase diagnostic accuracy, precision, and consistency in the use of terminology for definition. These efforts would include identifying and use gold-standard diagnostic approaches, including histological, cytological, microbiological, and microbial ecological data, to evaluate correlation with clinical signs or group of clinical signs used for metritis definition, among others.

The vaginal discharge characteristics most commonly used in the studies reviewed were described as a fetid red-brown watery vaginal discharge (39\%), as proposed 
in Sheldon et al. (2006). However, a surprising number of color, smell, and viscosity combinations were used to define clinical cases of PM, including purulent or mucopurulent content (35.6\%). The odor and viscosity of the vaginal discharge have been related to bacterial contamination on the uterine lumen. A study by Williams et al. (2005) found an association between the character and smell of the vaginal discharge in cows at 21 or 28 DIM; specifically, Trueperella pyogenes and Fusobacterium necrophorum were associated with mucopurulent or purulent content, whereas T. pyogenes and Escherichia coli were associated with the fetid smell of the discharge. Metritis can be caused by various microbes that result in varying vaginal discharge characteristics, that may or not be associated with infection severity. This increases the challenge of using vaginal discharge as the primary set of criteria for the case definition of PM.

The implications of PM polymicrobial characteristics has also been discussed in recent studies using metagenomic approaches to explore uterine bacterial community involved in PM, and corroborate for the hypothesis that common pathogens found using culturedependent associated with PM are in general observed at low relative abundance in cows with PM (Galvão et al., 2019). A recent review article focusing on studies that used metagenomic approaches to explore uterine bacterial community involved in PM concluded that PM is more likely an outcome of the dysbiosis of the uterine microbiota, which has been shown to result in high abundance of multiple anaerobic bacteria, such as Bacteroides, Porphyromonas, and Fusobacterium (Jeon and Galvão, 2018). More research is needed to expand the understanding of PM pathogenesis using sequencing technologies, including studies that can demonstrate causation for some of the new microbe identified as potential agents in PM pathogenesis, as well as effective visual clinical diagnosis approaches that will include diagnosis accuracy. The advancement of PM pathogenesis understanding can help identify targets that could be used to more accurately diagnose, treat and prevent PM in field settings. Future research aiming to validate the association among vaginal discharge characteristics and health and reproductive outcomes will be necessary to propose a consistent disease definition.

Fever was a common clinical sign used for PM diagnosis, being included in $59.7 \%$ of the studies as part of the disease definition. However, in $39.5 \%$ of the articles, it was mentioned but not used as part of the case definition of PM for cows. Fever is commonly outlined as a clinical sign for the definition of PM in literature (Sheldon et al., 2006). Nevertheless, fever alone has been shown as being an unreliable sole criterion for diagnosis of PM. Sannmann et al. (2013) reported that $36.8 \%$ of healthy cows had a rectal temperature $>39.5^{\circ} \mathrm{C}$ during the first 4 DIM, highlighting the lack of specificity of rectal temperature for defining PM. Furthermore, the rectal temperature of healthy postpartum dairy cows within the first 10 DIM is affected by several factors, including parity, DIM, time of the day, and temperature-humidity index (Suthar et al., 2012; Burfeind et al., 2014c), which can lead to an increase in both false-positive and false-negative rates for PM diagnosis. Additionally, in 5 articles included in the review, the rectal temperature threshold used to define fever was $>39.2^{\circ} \mathrm{C}$ instead of $>39.5^{\circ} \mathrm{C}$; the use of a lower-body temperature threshold could increase the number of false-positive cases (type I error), by increasing the number of cows diagnosed with PM when not present (Giuliodori et al., 2013). On the contrary, relying on fever for PM diagnosis alone can lead to the underdetection of PM cases, and consequently, an increased in false-negative rate (type II error), by diagnosing a cow with PM as not having PM. Benzaquen et al. (2007) reported that $58.5 \%$ of cows diagnosed with PM did not have a fever at the time of diagnosis. Therefore, rectal temperature could be used as a tool to identify febrile animals requiring further clinical evaluation to properly identify other systemic signs of disease or to provide adequate ancillary treatment based on potential systemic impact of PM.

Nonspecific signs of disease were mentioned in $28.7 \%$ of articles as part of the PM definition. A guideline developed in a study by LeBlanc (2008) suggested that antimicrobial treatment should be used in cows with at least 2 clinical signs of PM (e.g., fever, inappetence, or dullness, retained placenta, fetid uterine discharge). LeBlanc (2008) based the case definition for PM on best-known approaches and conceptual considerations, without an on-farm validation that included practicality, accuracy, and health and reproductive outcomes. Recent reports from a large on-farm study evaluating practices for diagnosis and treatment of PM revealed that current practices in farms lack agreement across dairies on criteria used for a case definition of PM and guide treatment decisions (Espadamala et al., 2018). Validation of criteria for on-farm diagnosis of PM and field supported data on the thresholds that should be used to guide treatment of PM having animal health; wellbeing, productivity, and antimicrobial stewardship in mind are needed to continue to support the implementation in field settings.

Although the most common tool used to obtain vaginal discharge was the rectal palpation with uterine massage $(37 \%)$, in $28 \%$ of publications, the diagnostic tool was not mentioned, which represents a weakness in the scientific rigor and replicability of the methods and a challenge to evaluate the accuracy of the proposed 
diagnosis. A review identifying relevant publications regarding the validity of diagnostic methods for PM reported 9 different diagnostic tools. Still, evidence supporting the use of those tools was described as weak or not reported (Sannmann et al., 2012). Diagnostic methods that do not exclusively rely on visual inspection have been evaluated for PM diagnosis, with varying success. For instance, the identification of biomarkers of inflammation, such as haptoglobin (Burfeind et al., 2014b; Barragan et al., 2018), has been evaluated and did not identify significant differences between healthy and metritic cows. Diagnosis of PM through behavioral changes (Stangaferro et al., 2016; Barragan et al., 2018; Neave et al., 2018), automated monitored systems tracking rumination and activity (Stangaferro et al., 2016), and electronic devices for sensory evaluation of the discharge (Burfeind et al., 2014a), among others, have also been evaluated to improved diagnostic accuracy. However, one of the main challenges to accurately diagnose PM is the lack of a gold standard. For this reason, the sensitivity and specificity of the available diagnostic methods are not reported or computed only compared with a reference method. This scoping review identified a knowledge gap in the available literature and a need for further research validating the diagnostic methods for PM to improve disease diagnostic accuracy, early treatment, and judicious use of antimicrobials when needed.

Within the articles including disease treatment, most of the treatment decisions relied on the assessment of the vaginal discharge $(38.1 \%)$ or the combination of discharge and fever $(47.6 \%)$, but in only $11.9 \%$ of articles were other clinical signs used to initiate antimicrobial treatment. The 2 main objectives of treating cows that suffer from PM are improving welfare and maintaining reproductive and productive efficiency (LeBlanc, 2008). Ceftiofur, a third-generation cephalosporin, has been reported as the most common antimicrobial used for treating metritic cows in the United States. A meta-analysis conducted by Haimerl et al. (2017), concluded that ceftiofur was the only antimicrobial drug supported by clinical trials that showed a decreased prevalence of PM in treated cows compared with the control group. However, there is limited evidence of the benefit of antimicrobial therapy for PM cases aside from improvement of fever (McLaughlin et al., 2012). A $21.8 \%$ spontaneous cure rate has been reported when antimicrobial therapy was delayed until the fifth day postpartum when cows were followed during the first 10 DIM, which could imply a reduction in antimicrobial use in cows with PM that recovered within the first 5 d (Sannmann et al., 2013) or, spontaneous cure $12 \mathrm{~d}$ after diagnosis in $64.6 \%$ of untreated cows with PM (Machado et al., 2020). Aside from this, there are rising concerns with antimicrobial resistance and pressure toward improving antimicrobial drug stewardship on dairy farms (Tragesser et al., 2006; Taylor et al., 2019). On large dairy operations, the identification and treatment of sick animals are commonly conducted by farm employees; a study by Espadamala et al. (2018) observed a lack of consensus on dairies in California regarding the clinical signs of disease used for PM diagnosis and consequent treatment of cows, in addition to a significant variation in antimicrobial drug selected, dose, and treatment duration. A core principle of antimicrobial stewardship is the judicious use of antimicrobials including the proper antimicrobial drug selection, the correct dose, duration, and route of administration (AVMA). The inconsistent and subjective criteria used for PM definition, creates challenges for precise treatment threshold and cure definitions, which is required to develop clear treatment protocols on the farm that help decide which cases will benefit from antimicrobial treatment and reliable definition of treatment success.

Our scoping review protocol was designed to be inclusive, and we did not screen articles based on their scientific rigor. Thus, it is unknown if PM definition differs based on the quality of the included studies. Our studies were limited to English language; however, this may have created a selection bias and affected our findings. Future scoping reviews may include relevant studies from other languages or translation resources of literature. In addition, the lack of reporting on the data items charted for the review was a prevalent finding in most of the relevant studies, which influence the scientific rigor and replicability of the methods of some studies and may have affected our results.

\section{CONCLUSIONS}

This scoping review describes a disparity in robust and clear criteria used to diagnose PM in literature. Specific criteria observed to commonly be used, that displayed large variation between manuscripts was vaginal discharge odor, and viscosity characteristics, fever, and DIM. There was also a considerable variation in the clinical signs of disease used for diagnosis and consequent treatment decision. Although select consensus articles are available, they are frequently not used, and disparity in terminology used to define visual clinical signs of PM (e.g., odor and color of vaginal discharge) highlight the need for further high-quality research to establish a standardized case definition for PM.

\section{ACKNOWLEDGMENTS}

We thank the University of California-Davis librarians Deanna Johnson and Megan Van Noord for their 
support for this project. This work is supported by grant no. 2018-68003-27466 from the USDA National Institute of Food and Agriculture. Any opinions, findings, conclusions, or recommendations expressed in this publication are those of the author(s) and do not necessarily reflect the view of the USDA. The authors have not stated any conflicts of interest.

\section{REFERENCES}

Arksey, H., and L. O'Malley. 2005. Scoping studies: Towards a methodological framework. Int. J. Soc. Res. Methodol. 8:19-32. https:/ /doi.org/10.1080/1364557032000119616.

AVMA (American Veterinary Medical Association). 2019. Veterinary Checklist for Antimicrobial Stewardship. AVMA.

AVMA Committee on Antimicrobials. 2020. Antimicrobial-Resistant Pathogens Affecting Animal Health in the United States. AVMA.

Barragan, A. A., J. M. Piñeiro, G. M. Schuenemann, P. J. RajalaSchultz, D. E. Sanders, J. Lakritz, and S. Bas. 2018. Assessment of daily activity patterns and biomarkers of pain, inflammation, and stress in lactating dairy cows diagnosed with clinical metritis. J. Dairy Sci. 101:8248-8258. https://doi.org/10.3168/jds.2018-14510.

Benzaquen, M. E., C. A. Risco, L. F. Archbald, P. Melendez, M.-J. Thatcher, and W. W. Thatcher. 2007. Rectal temperature, calving-related factors, and the incidence of puerperal metritis in postpartum dairy cows. J. Dairy Sci. 90:2804-2814. https://doi.org/10 $.3168 /$ jds.2006-482.

Burfeind, O., M. Bruins, A. Bos, I. Sannmann, R. Voigtsberger, and W. Heuwieser. 2014a. Diagnosis of acute puerperal metritis by electronic nose device analysis of vaginal discharge in dairy cows. Theriogenology 82:64-70. https://doi.org/10.1016/j.theriogenology 2014.03.001.

Burfeind, O., I. Sannmann, R. Voigtsberger, and W. Heuwieser. 2014b. Receiver operating characteristic curve analysis to determine the diagnostic performance of serum haptoglobin concentration for the diagnosis of acute puerperal metritis in dairy cows. Anim. Reprod. Sci. 149:145-151. https://doi.org/10.1016/j.anireprosci.2014 .07 .020 .

Burfeind, O., V. S. Suthar, R. Voigtsberger, S. Bonk, and W. Heuwieser. 2014c. Body temperature in early postpartum dairy cows. Theriogenology 82:121-131. https://doi.org/10.1016/j.theriogenology 2014.03.006

Chenault, J. R., J. F. McAllister, S. T. Chester, K. J. Dame, F. M. Kausche, and E. J. Robb. 2004. Efficacy of ceftiofur hydrochloride sterile suspension administered parenterally for the treatment of acute postpartum metritis in dairy cows. J. Am. Vet. Med. Assoc. 224:1634-1639. https://doi.org/10.2460/javma.2004.224.1634.

de Oliveira, E. B., F. Cunha, R. Daetz, C. C. Figueiredo, R. C. Chebel, J. E. Santos, C. A. Risco, K. C. Jeong, V. S. Machado, and K. N. Galvão. 2020. Using chitosan microparticles to treat metritis in lactating dairy cows. J. Dairy Sci. 103:7377-7391. https://doi.org/ 10.3168/jds.2019-18028.

Dohmen, M. J. W., J. A. C. M. Lohuis, G. Huszenicza, P. Nagy, and M. Gacs. 1995. The relationship between bacteriological and clinical findings in cows with subacute/chronic endometritis. Theriogenology 43:1379-1388. https://doi.org/10.1016/0093-691X(95)00123 $-\mathrm{P}$.

Drillich, M., O. Beetz, A. Pfützner, M. Sabin, H.-J. Sabin, P. Kutzer, H. Nattermann, and W. Heuwieser. 2001. Evaluation of a systemic antibiotic treatment of toxic puerperal metritis in dairy cows. J. Dairy Sci. 84:2010-2017. https://doi.org/10.3168/jds.S0022 -0302(01)74644-9.

Drillich, M., D. Voigt, D. Forderung, and W. Heuwieser. 2007. Treatment of acute puerperal metritis with flunixin meglumine in addition to antibiotic treatment. J. Dairy Sci. 90:3758-3763. https:// doi.org/10.3168/jds.2007-0052.

Dubuc, J., T. F. Duffield, K. E. Leslie, J. S. Walton, and S. J. LeBlanc. 2011. Effects of postpartum uterine diseases on milk production and culling in dairy cows. J. Dairy Sci. 94:1339-1346. https://doi .org $/ 10.3168 /$ jds.2010-3758.

Elkjær, K., R. Labouriau, M. L. Ancker, H. Gustafsson, and H. Callesen. 2013. Short communication: Large-scale study on effects of metritis on reproduction in Danish Holstein cows. J. Dairy Sci. 96:372-377. https://doi.org/10.3168/jds.2012-5584.

Espadamala, A., R. Pereira, P. Pallarés, A. Lago, and N. Silva-delRío. 2018. Metritis diagnosis and treatment practices in 45 dairy farms in California. J. Dairy Sci. 101:9608-9616. https://doi.org/ 10.3168/jds.2017-14296.

Galvão, K. N., R. C. Bicalho, and S. J. Jeon. 2019. Symposium review: The uterine microbiome associated with the development of uterine disease in dairy cows. J. Dairy Sci. 102:11786-11797.

Garzon, A., G. Habing, F. Lima, N. Silva-del-Río, F. Samah, and R. Pereira. 2021. Supplemental materials. Defining clinical diagnosis and treatment of puerperal metritis in dairy cows: A scoping review. https://doi.org/10.5281/zenodo.5576632.

Giuliodori, M. J., R. P. Magnasco, D. Becu-Villalobos, I. M. LacauMengido, C. A. Risco, and R. L. de la Sota. 2013. Metritis in dairy cows: Risk factors and reproductive performance. J. Dairy Sci 96:3621-3631. https://doi.org/10.3168/jds.2012-5922.

Gorden, P. J., J. A. Ydstie, M. D. Kleinhenz, L. W. Wulf, R. Gehring, C. J. Lee, C. Wang, and J. F. Coetzee. 2016. A study to examine the relationship between metritis severity and depletion of oxytetracycline in plasma and milk after intrauterine infusion. J. Dairy Sci. 99:8314-8322. https://doi.org/10.3168/jds.2016-10959.

Gordis, L. 2009. Epidemiology. 4th edition. Elsevier.

Haimerl, P., S. Arlt, S. Borchardt, and W. Heuwieser. 2017. Antibiotic treatment of metritis in dairy cows - A meta-analysis. J. Dairy Sci. 100:3783-3795. https://doi.org/10.3168/jds.2016-11834.

Hammon, D. S., I. M. Evjen, T. R. Dhiman, J. P. Goff, and J. L. Walters. 2006. Neutrophil function and energy status in Holstein cows with uterine health disorders. Vet. Immunol. Immunopathol. 113:21-29. https://doi.org/10.1016/j.vetimm.2006.03.022.

Hooijmans, C. R., M. M. Rovers, R. B. M. De Vries, M. Leenaars, M. Ritskes-Hoitinga, and M. W. Langendam. 2014. SYRCLE's risk of bias tool for animal studies. BMC Med. Res. Methodol. 14:43. https://doi.org/10.1186/1471-2288-14-43.

Huzzey, J. M., D. M. Veira, D. M. Weary, and M. A. G. von Keyserlingk. 2007. Prepartum behavior and dry matter intake identify dairy cows at risk for metritis. J. Dairy Sci. 90:3220-3233. https:/ /doi.org/10.3168/jds.2006-807.

Jeon, S. J., and K. N. Galvão. 2018. An advanced understanding of uterine microbial ecology associated with metritis in dairy cows. Genomics Inform. 16:e21. https://doi.org/10.5808/GI.2018.16.4 .e21.

Jeon, S. J., A. Vieira-Neto, M. Gobikrushanth, R. Daetz, R. D. Mingoti, A. C. B. Parize, S. L. de Freitas, A. N. L. da Costa, R. C. Bicalho, S. Lima, K. C. Jeong, and K. N. Galvão. 2015. Uterine microbiota progression from calving until establishment of metritis in dairy cows. Appl. Environ. Microbiol. 81:6324-6332. https://doi .org/10.1128/AEM.01753-15.

LeBlanc, S. J. 2008. Postpartum uterine disease and dairy herd reproductive performance: A review. Vet. J. 176:102-114. https://doi .org/10.1016/j.tvjl.2007.12.019.

Lima, F. S., A. Vieira-Neto, J. A. Snodgrass, A. De Vries, and J. E. P. Santos. 2019. Economic comparison of systemic antimicrobial therapies for metritis in dairy cows. J. Dairy Sci. 102:7345-7358. https://doi.org/10.3168/jds.2018-15383.

Lima, F. S., A. Vieira-Neto, G. S. F. M. Vasconcellos, R. D. Mingoti, E. Karakaya, E. Solé, R. S. Bisinotto, N. Martinez, C. A. Risco, K. N. Galvão, and J. E. P. Santos. 2014. Efficacy of ampicillin trihydrate or ceftiofur hydrochloride for treatment of metritis and subsequent fertility in dairy cows. J. Dairy Sci. 97:5401-5414. https:/ /doi.org/10.3168/jds.2013-7569.

Machado, V. S., M. L. Celestino, E. B. Oliveira, F. S. Lima, M. A. Ballou, and K. N. Galvão. 2020. The association of cow-related factors assessed at metritis diagnosis with metritis cure risk, reproductive performance, milk yield, and culling for untreated and ceftiofurtreated dairy cows. J. Dairy Sci. 103:9261-9276. https://doi.org/ 10.3168/jds.2020-18643. 
Martinez, N., C. A. Risco, F. S. Lima, R. S. Bisinotto, L. F. Greco, E. S. Ribeiro, F. Maunsell, K. Galvão, and J. E. P. Santos. 2012. Evaluation of peripartal calcium status, energetic profile, and neutrophil function in dairy cows at low or high risk of developing uterine disease. J. Dairy Sci. 95:7158-7172. https://doi.org/10 $.3168 /$ jds.2012-5812.

McDougall, S., R. Macaulay, and C. Compton. 2007. Association between endometritis diagnosis using a novel intravaginal device and reproductive performance in dairy cattle. Anim. Reprod. Sci. 99:923. https://doi.org/10.1016/j.anireprosci.2006.03.017.

McLaughlin, C. L., E. Stanisiewski, M. J. Lucas, C. P. Cornell, J. Watkins, L. Bryson, J. K. S. Tena, J. Hallberg, and J. R. Chenault. 2012. Evaluation of two doses of ceftiofur crystalline free acid sterile suspension for treatment of metritis in lactating dairy cows. J. Dairy Sci. 95:4363-4371. https://doi.org/10.3168/jds.2011-5111.

McLaughlin, C. L., E. P. Stanisiewski, C. A. Risco, J. E. P. Santos, G. E. Dahl, R. C. Chebel, C. LaGrow, C. Daugherty, L. Bryson, D. Weigel, J. Hallberg, and M. J. Lucas. 2013. Evaluation of ceftiofur crystalline free acid sterile suspension for control of metritis in high-risk lactating dairy cows. Theriogenology 79:725-734. https:/ /doi.org/10.1016/j.theriogenology.2012.11.029.

Murray, R. D., J. D. Allison, and R. P. Gard. 1990. Bovine endometritis: Comparative efficacy of alfaprostol and intrauterine therapies, and other factors influencing clinical success. Vet. Rec. 127:86-90.

Neave, H. W., J. Lomb, D. M. Weary, S. J. LeBlanc, J. M. Huzzey, and M. A. G. von Keyserlingk. 2018. Behavioral changes before metritis diagnosis in dairy cows. J. Dairy Sci. 101:4388-4399. https:// doi.org/10.3168/jds.2017-13078.

Piccardi, M., G. Romero, G. Veneranda, E. Castello, D. Romero, M. Balzarini, and G. A. Bó. 2016. Effect of puerperal metritis on reproductive and productive performance in dairy cows in Argentina. Theriogenology 85:887-893. https://doi.org/10.1016/j theriogenology.2015.10.038.

Sannmann, I., S. Arlt, and W. Heuwieser. 2012. A critical evaluation of diagnostic methods used to identify dairy cows with acute postpartum metritis in the current literature. J. Dairy Res. 79:436-444. https://doi.org/10.1017/S0022029912000519.

Sannmann, I., O. Burfeind, R. Voigtsberger, and W. Heuwieser. 2013. Comparison of two monitoring and treatment strategies for cows with acute puerperal metritis. Theriogenology 79:961-969. https:/ /doi.org/10.1016/j.theriogenology.2013.01.016.

Sannmann, I., and W. Heuwieser. 2015. Technical note: Intraobserver, interobserver, and test-retest reliabilities of an assessment of vaginal discharge from cows with and without acute puerperal metritis. J. Dairy Sci. 98:5460-5466. https://doi.org/10.3168/jds .2014-9169

Sargeant, J. M., M. D. Bergevin, K. Churchill, K. Dawkins, B. Deb, J. Dunn, C. M. Logue, A. Novy, A. M. O'Connor, M. Reist, and C. B. Winder. 2019. The efficacy of antibiotics to control colibacillosis in broiler poultry: A systematic review. Anim. Health Res. Rev. 20:263-273. https://doi.org/10.1017/S1466252319000264.

Sargeant, J. M., and A. M. O'Connor. 2014. Conducting systematic reviews of intervention questions II: Relevance screening, data extraction, assessing risk of bias, presenting the results and interpreting the findings. Zoonoses Public Health 61(Suppl 1):39-51. https: //doi.org/10.1111/zph.12124.

Sheldon, I. M., G. S. Lewis, S. LeBlanc, and R. O. Gilbert. 2006. Defining postpartum uterine disease in cattle. Theriogenology 65:1516-1530. https://doi.org/10.1016/j.theriogenology.2005.08 .021 .

Sheldon, I. M., and D. E. Noakes. 1998. Comparison of three treatments for bovine endometritis. Vet. Rec. 142:575-579. https://doi . org $/ 10.1136 /$ vr.142.21.575.

Sheldon, I. M., D. E. Noakes, A. N. Rycroft, and H. Dobson. 2002. Effect of postpartum manual examination of the vagina on uterine bacterial contamination in cows. Vet. Rec. 151:531-534. https:// doi.org/10.1136/vr.151.18.531.

Sheldon, I. M., E. J. Williams, A. N. A. Miller, D. M. Nash, and S. Herath. 2008. Uterine diseases in cattle after parturition. Vet. J. 176:115-121. https://doi.org/10.1016/j.tvjl.2007.12.031.
Smith, B. I., G. Arthur Donovan, C. Risco, R. Littell, C. Young, L. H. Stanker, and J. Elliott. 1998. Comparison of various antibiotic treatments for cows diagnosed with toxic puerperal metritis. J. Dairy Sci. 81:1555-1562. https://doi.org/10.3168/jds.S0022 -0302(98)75721-2.

Stangaferro, M. L., R. Wijma, L. S. Caixeta, M. A. Al-Abri, and J. O. Giordano. 2016. Use of rumination and activity monitoring for the identification of dairy cows with health disorders: Part III. Metritis. J. Dairy Sci. 99:7422-7433. https://doi.org/10.3168/jds .2016-11352.

Stevenson. J. S. 2007. Clinical Reproductive Physiology of the Cow. 2nd edition. R. Youngquist and W. Threlfall, ed. W.B. Saunders.

Stojkov, J., M. A. G. von Keyserlingk, J. N. Marchant-Forde, and D. M. Weary. 2015. Assessment of visceral pain associated with metritis in dairy cows. J. Dairy Sci. 98:5352-5361. https://doi.org/10 $.3168 /$ jds.2014-9296.

Suthar, V., O. Burfeind, S. Bonk, R. Voigtsberger, C. Keane, and W. Heuwieser. 2012. Factors associated with body temperature of healthy Holstein dairy cows during the first 10 days in milk. J. Dairy Res. 79:135-142. https://doi.org/10.1017/S0022029911000896.

Taylor, E. A., E. R. Jordan, J. A. Garcia, G. R. Hagevoort, K. N. Norman, S. D. Lawhon, J. M. Piñeiro, and H. M. Scott. 2019. Effects of two-dose ceftiofur treatment for metritis on the temporal dynamics of antimicrobial resistance among fecal Escherichia coli in Holstein-Friesian dairy cows. PLoS One 14:e0220068. https:// doi.org/10.1371/journal.pone.0220068.

Tragesser, L. A., T. E. Wittum, J. A. Funk, P. L. Winokur, and P. J. Rajala-Schultz. 2006. Association between ceftiofur use and isolation of Escherichia coli with reduced susceptibility to ceftriaxone from fecal samples of dairy cows. Am. J. Vet. Res. 67:1696-1700. https://doi.org/10.2460/ajvr.67.10.1696.

Tricco, A. C., E. Lillie, W. Zarin, K. K. O'Brien, H. Colquhoun, D. Levac, D. Moher, M. D. J. Peters, T. Horsley, L. Weeks, S. Hempel, E. A. Akl, C. Chang, J. McGowan, L. Stewart, L. Hartling, A. Aldcroft, M. G. Wilson, C. Garritty, S. Lewin, C. M. Godfrey, M. T. MacDonald, E. V. Langlois, K. Soares-Weiser, J. Moriarty, T. Clifford, Ö. Tunçalp, and S. E. Straus. 2018. PRISMA extension for scoping reviews (PRISMA-ScR): Checklist and explanation. Ann. Intern. Med. 169:467-473. https://doi.org/10.7326/M18-0850.

Urton, G., M. A. G. von Keyserlingk, and D. M. Weary. 2005. Feeding behavior identifies dairy cows at risk for metritis. J. Dairy Sci. 88:2843-2849. https://doi.org/10.3168/jds.S0022-0302(05)72965 $-9$.

USDA. 2008. Antibiotic Use on U.S. Dairy Operations, 2002 and 2007. USDA. Animal and Plant Health Inspection Service.

USDA. 2018. Dairy 2014: Health and Management Practices on U.S. Dairy Operations, 2014. USDA, Animal and Plant Health Inspection Service, Veterinary Services, Center for Epidemiology and Animal Health, and National Animal Health Monitoring System.

Williams, E. J., D. P. Fischer, D. U. Pfeiffer, G. C. W. England, D. E. Noakes, H. Dobson, and I. M. Sheldon. 2005. Clinical evaluation of postpartum vaginal mucus reflects uterine bacterial infection and the immune response in cattle. Theriogenology 63:102-117. https: //doi.org/10.1016/j.theriogenology.2004.03.017.

\section{ORCIDS}

Adriana Garzon @ https://orcid.org/0000-0003-3464-6670 Gregory Habing (ํ) https://orcid.org/0000-0002-0855-7650 Fabio Lima @ https://orcid.org/0000-0001-8377-6469 Noelia Silva-del-Rio @ $\odot$ https://orcid.org/0000-0002-2826-6797 Festus Samah 1 https://orcid.org/0000-0002-6525-5448 Richard Pereira @ https://orcid.org/0000-0003-2028-8761 